\title{
Study the Effects of Formaldehyde and Xylene Vapor on Lung and Testicular Tissue with Sperm Morphology of Adult Albino Rats
}

\author{
Treefa F. Ismail', Galawezh O. Othman', Naznaz H. Othman ${ }^{2 *}$, Ban A. Hasan ${ }^{3}$ \\ ${ }^{1}$ Department of Biology, College of Education, Salahaddin University, Erbil, Kurdistan Region, Iraq, ${ }^{2}$ Department of Pharmacy, Erbil Medical \\ Technical Institute, Erbil Polytechnic University, Kurdistan Region, Iraq, ${ }^{3}$ Department of Density, College of Density, University of Al kitab, \\ Kirkuk, Iraq
}

\author{
${ }^{*}$ Corresponding author: \\ Naznaz H. Othman, \\ Department of \\ Pharmacy, Erbil Medical \\ Technical Institute, Erbil \\ Polytechnic University, \\ Kurdistan Relegion, Iraq. \\ E-mail: naznaz.othman@ \\ epu.edu.iq
}

Received: 29 September 2020

Accepted: 28 February 2021

Published: 30 June 2021

DOI

10.25156/pti.v11n1y2021.pp46-51

\section{A B S T R A C T}

Formalin is widely used chemical substance in industry and medicine (as tissue fixative and disinfectant). It contains reactive molecules which have been known for its cytotoxic effects. Furthermore, xylene used in histological techniques during preparation of tissue and has different toxic effects on tissues. The present study was performed to investigate the effects of formaldehyde and xylene inhalation on albino rat's lung and testes. Fifteen adult male rats were used in this study; the rats were divided randomly into three groups (A, B, and C). Group (A) comprises the control group, whereas the rats in the Group (B) were exposed to $10 \%$ formaldehyde vapor and the rats from Group (C) were exposed to xylene vapor for $4 \mathrm{~h} /$ day for 5 days/week for 1 month. Histological alterations were observed in the lung of formalin and xylene exposed rats manifested by lymphatic infiltration, emphysema, congestion, dilation of blood vessels, and alveolar sac and also thinning in the wall of alveolar bronchiole. On the other hand, formaldehyde and xylene affected the testes tissue of treated rats including atrophy in the seminiferous tubule cells, edematous connective tissue, degenerative of spermatogenesis, depletion in germinal layer, existing of vacuoles in the seminiferous tubules, and decrease in the number of sperms in the lumen of seminiferous tubules. Furthermore, sperms abnormalities were seen. The data of our study concluded that inhalation the vapor of formaldehyde and xylene has degenerative effects on lungs and testes of the experimental rats as well as affecting on the spermatocytes and increased the frequency of sperm abnormalities.

Keywords: Formaldehyde; Lung; Sperm abnormalities; Testicular toxicity; Xylene

\section{INTRODUCTION}

Fomaldehyde is well known chemical and industry substances a preservative, sterilizer, and embalming fluids; it is a colorless, flammable gas at room temperature, has a pungent, distinct odor, and may cause a burning sensation to the eyes, nose, and lungs at high concentrations (OSHA, 1995). Domestic exposures occur mainly from consumer products that include textiles, insulation, paper, cosmetics, and wood products. Formalin is the aqueous solution of formaldehyde, usually used in fixation in 10\% (Feinman, 1988). Formaldehyde exposure has toxic effects on respiratory system, gastrointestinal tract, hematopoietic tissue, and nervous system (Mohamed et al., 2012; ALSaraj and AL-Hubaity, 2003; Turkoglu et al., 2008). Many studies showed that exposure to formaldehyde cause serious of harm effects on the respiratory system of the treated animals. Long-term formaldehyde inhalation at a dose of $15 \mathrm{ppm}$ was induced squamous cell carcinomas in the nasal cavities of rats and mice (Collins and Lineker,
2004; Fujimaki et al., 2004). It is irritating the mucous membranes of the nose, throat, and eyes even at very low concentrations below 1 ppm (WHO, 1999; WHO, 2006). Carpet factory workers who occupationally exposed to formaldehyde were presented loss of respiratory function (Jayalakshmi et al., 2011). Formaldehyde is recognized as toxic at certain doses and the chances of harmful effects are increased at room temperature due to its volatility. The toxicity of formaldehyde is of concern to all who work closely with it such as embalmers, anatomists, histology technicians, and medical students are among the people who have high exposure to formaldehyde (Pinkerton et al., 2004).

Commercial xylene is a colorless liquid produced from petroleum or coal tar and is one of the most commonly used solvents in industry, it is commonly used as a motor and aviation fuel additive, a solvent in the paint, printing, rubber and leather industries, a starting material in the plastics and textile industries, a carrier in the production of epoxy 
resins and a constituent of paint, lacquers, varnishes, inks, dyes, adhesives, and cleaning fluids (EPA, 2012). Xylene can be absorbed into the human body through inhalation, ingestion, or dermal (ATSDR, 2007). Acute inhalation exposure to mixed xylene in humans has been associated with shortness of breath, and irritation of the nose and throat; gastrointestinal effects (e.g. nausea, vomiting, and gastric discomfort); mild transient eye irritation; and neurological effects (e.g. impaired short-term memory, impaired reaction time, decreases in numerical ability, and alterations in equilibrium and body balance) (EPA, 2003). Other effects reported from chronic exposure include labored breathing, impaired pulmonary function, increased heart palpitation, severe chest pain, abnormal EKG, and possible effects on the kidneys. Mixed xylenes have not been extensively tested for chronic effects, although animal studies show effects on the liver and CNS from inhalation and oral exposures and effects on the kidneys from oral exposure to mixed xylenes (Fishman et al., 2008).

On the other hand, environmental pollutants such as xylene, formaldehyde, ethane dimethane sulfonates, thinner, toluene, and methanol have a negative effect on the function and structure of the testis tissue (Handagama and Ariyaratne, 2001; Karimov et al., 2003). In studies conducted on rats, xylene and formaldehyde caused testicular atrophy and decreases in testes weight and serum testosterone level, diameter of seminiferous tubules, and seminiferous epithelial height (Ozen et al., 2005). Formaldehyde with emphasizing on reproductive disorders including histological adverse effects on the testicular tissue, spermatogenesis, sperm viability, count, and the abnormalities which can potentially causes infertility after sexual maturation (Razi et al., 2013). The effects of formaldehyde were severe on exposed rabbits in the form of decrease the sperm count, motility, and increase the abnormal forms of sperms that were appear as in George et al., 1999. Furthermore, 10\% formalin triggered oxidative stress in testicles with the evidence of the significant increase of MDA concentration in rats exposed to formalin by inhalation (Cassidy et al., 1983).

\section{MATERIALS AND METHODS}

\section{Animals and Experimental Design}

Fifteen adult male rats aged 10 weeks and weighing (300$350 \mathrm{~g})$ were used in this study. They were housed in plastic cages $(56 \mathrm{~cm} \times 39 \mathrm{~cm} \times 19 \mathrm{~cm})$, bedded with wooden chips in the animal house of Biology Department/College of Education/Salahaddin University-Erbil. Animals were kept under standard laboratory conditions $12 \mathrm{~h}$ light: $12 \mathrm{~h}$ dark with controlled temperature of $22 \pm 2{ }^{\circ} \mathrm{C}$. The rats were divided randomly into three groups, each group five rats, Group A served as control group housed in separate room and Groups B, C served as the experimental group that housed away from each other. Control group was not exposed neither to formaline nor Xylene, Group B exposed to formalin vapor, and Group $\mathrm{C}$ exposed to Xylene vapor. The exposure was done by soaking cotton wool in the formaldehyde (10\%) and the soacked cotton was hanged $30 \mathrm{~cm}$ above the cage of the rats thus, exposing the animal to the vapor. The rats in the Group $\mathrm{C}$ were exposed to the xylene vapor in the same manner that was applied to the group B. The exposure to formalin was applied for $4 \mathrm{~h} /$ day for 5 days/week for 1 month.

\section{Histological Studies}

At the end of experiment, the animals were prepared for dissecting. All animals were anesthetized with ketamine hydrochloride $(100 \mathrm{mg} / \mathrm{kg} \mathrm{B} . \mathrm{W}$.), lung and testis were excised then cut into small pieces $\left(<0.5 \mathrm{~cm}^{3}\right.$ in thickness) and kept in the fixative. Following was the process of histological preparation, the organs fixed in Bouine fixative for $24 \mathrm{~h}$ to harden the tissue, and inactivates enzymes that might otherwise degrade the tissue, then processed for paraffin method by dehydrating through ascending concentrations of ethanol $(50 \%, 70 \%, 95 \%$, and $100 \%)$, each for $1 \mathrm{~h}$, cleared in xylene three time each for $1 \mathrm{~h}$, infiltrated in paraffin wax also three time each for $1 / 2 \mathrm{~h}$ in oven at $60^{\circ} \mathrm{C}$ and finally embedded in paraffin wax. Sections were cut at $5 \mu \mathrm{m}$ thickness with a rotary microtome. The sections were stained by hematoxylin and eosin (Bancroft and Gamble, 2002).

\section{Sperm Preparation}

Using the method described by Karanowska (1976), the sperm film from epididymis and vas deferens was prepared. The epididymis and vas deference were put in a small petridish containing $90 \%$ of normal saline. Then, the sperm was extracted, smeared, and stained using 1\% Eosin for $10 \mathrm{~min}$. Sperms were counted and the data were analyzed by completely randomized design. Then, all the abnormal sperms were examined.

\section{RESULTS AND DISCUSSION}

\section{Formalin and Xylene Effects on Lung}

The lung is the essential organ of respiration and the organ that receives the entire cardiac output. Furthermore, the lung plays an important role in host defense and regulation of circulating levels of biologically active materials by extensive surface of pulmonary vascular bed (Fishman et al., 2008). It is well known that chronic formaldehyde exposure has an irritant effect on the respiratory tract and induces adverse alterations in respiratory-function parameters and cellular morphology (Fujimaki et al., 2004). 
Figure 1 illustrates the lung of the control group in which normal pulmonary tissue architecture with clear patent bronchial passages and alveolar cavities including the alveolar sacs, the alveolar ducts, and the alveoli. Pulmonary vessels were normally distributed within the pulmonary parenchyma. The alveolar septa had normal thickness with no abnormality in alveolar septal blood capillaries.

Our result showed that formaldehyde inhalation affected the histological structure of the lung in the treated rats [Figure 2] in which highly lymphatic infiltration and congestion of blood cells between the alveolar sacs. While [Figure 3] showed other alteration in the histological structure of the lung of formaldehyde treated rats including dilation in alveolar sac and thickening in the alveolar wall, which are abnormal features for lung and also emphysema and cellular infiltration were seen in other sections of formaldehyde treated rat lungs. There are numerous reports supported our result that formaldehyde affected the lung

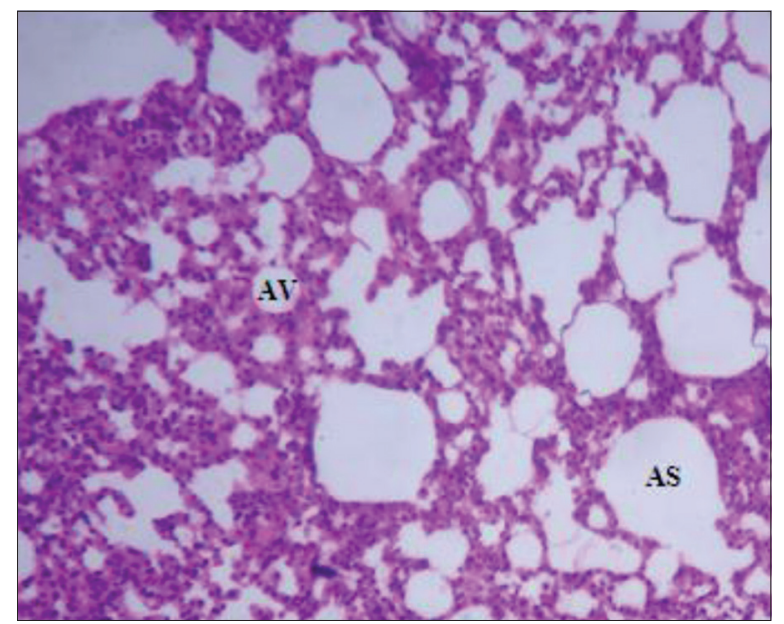

Figure 1: Section through the lung of control group showing normal alveolus (AV) and alveolar sac (AS) 100x

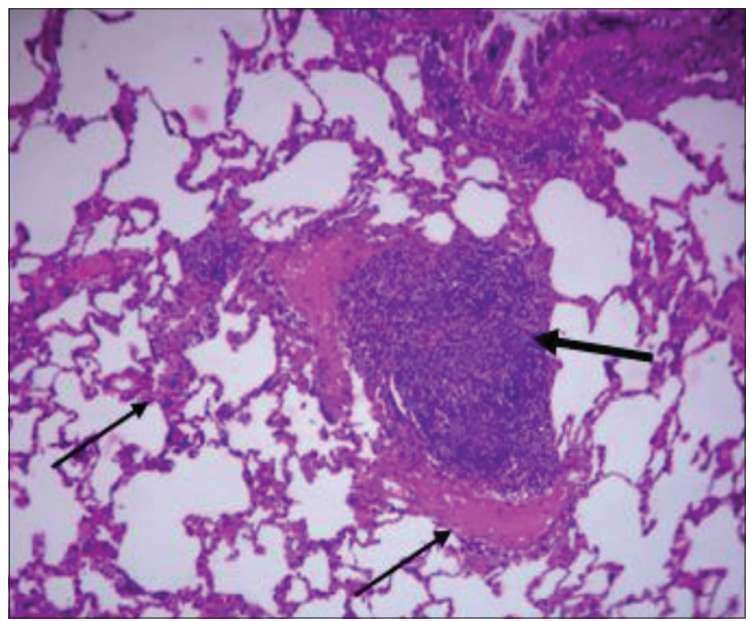

Figure 2: Section through the lung of formaldehyde exposed group showing lymphatic infiltration (thick arrow) and congestion of red blood cells between the alveolar sac (thin arrow) 100x as in Figure 4 demonstrated that formaldehyde inhalation caused congestion in most lobes, destructed blood gas barrier, inflammatory exudates, thickened and dilatation of interalveolar septal capillaries, and dilatation of the pulmonary blood vessels. Another study by Shrivastava and Saxena, 2013, on medical student demonstrate that acute exposure to formalin for $2 \mathrm{~h} /$ day for 6 days/week throughout the year resulted in decrease in the dynamic lung function tests FFVC, FEV1\%, FEF25-75, and PEFR except FEV1 indicating mild bronchoconstriction. Furthermore, the microscopic examination of the lung of formaldehyde exposed group showed that fatty and cellular infiltration in the pulmonary interstitium and thickening in the bronchiolar wall were evident. Dilatation and congestion were prominent in the alveolar septal vessels (Turkoglu et al., 2008)

On the other hand, xylene has other histological changes in the lung of treated rats included emphysema which

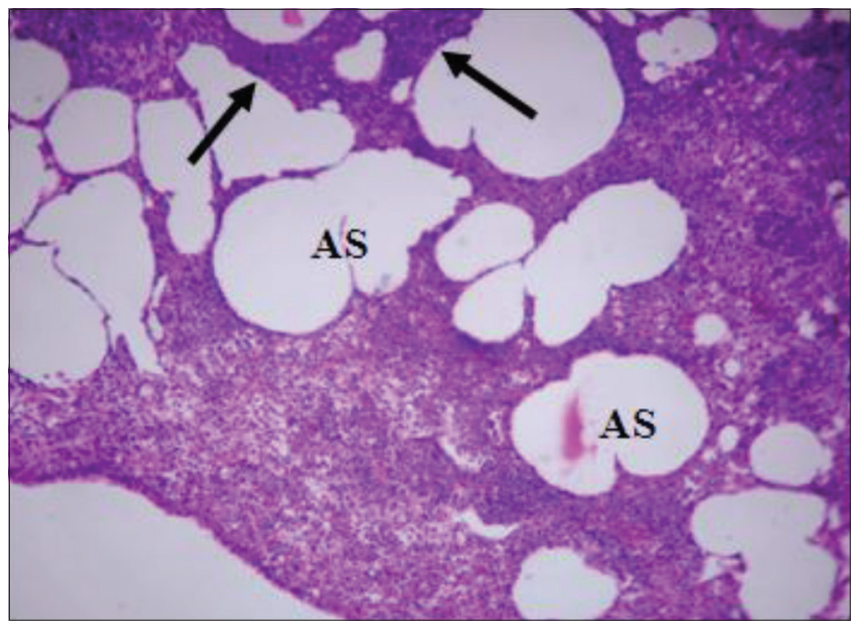

Figure 3: Section through the lung of formaldehyde exposed group showing dilation in the alveolar sac (AS) and thickening in the alveolar wall (arrow) 100x

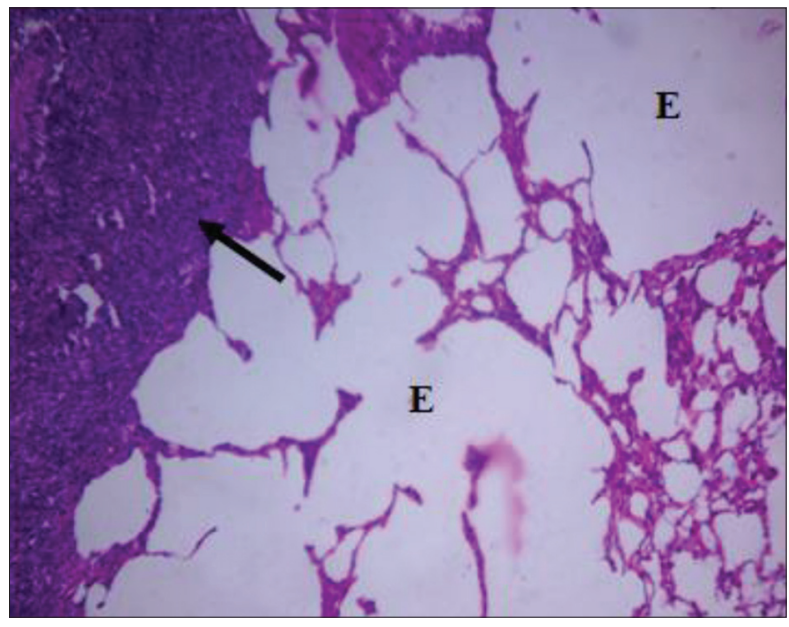

Figure 4: Section through the lung of formaldehyde exposed group showing emphysema (E) and cellular infiltration (arrow) 100x 
is thinning in the wall of the alveolar sac and broken in some place to be larger alveoli than normal and dilation in the blood vessel with highly congestion of erythrocytes between the alveolar sacs and hyper plastic smooth muscle of its wall [Figures 5 and 6]. Many studies on toxic effects of xylene revealed similar results of xylene on different organs and tissues including respiratory system (nasal epithelium, trachea and lung), in which different histological alteration showed in treated animals and workers in histological techniques laboratories (ATSDR, 2007; Fishman et al., 2008). Similar results were observed in the study of Arslan et al., (2016), in which xylene caused degenerative effects in the lining epithelium of respiratory mucosa include loss of ciliated cells with metaplasia of goblet cells, hyperplasia of squamous cells and edema, inflammation in sub epithelial area. Xylene fume altered the histoarchitecture of lung and esterase and collagen wall, this ranged from mild emphysematous change, inflammation of cells, Collapse of the collagen wall, and distortion of esterase (Samuel et al., 2018).

\section{Formalin and Xylene Effects on Testes}

In control rats, testicular histology revealed normal spermatogenesis depicting all the germ cells types, normal closely seminiferous epithelium with large number of sperms in the lumen of seminiferous tubules. Interstitial Leydig cells also showed normal morphology and number in the space between the seminiferous tubules [Figure $7 \mathrm{a}$ and $\mathrm{b}$ ]. In testes of formaldehyde exposed rats, degenerative changes in the seminiferous epithelium were characterized by the cytoplasmic vacuolization, no sperms in tubular lumen were seen, edematous connective tissue between the tubules and small numbers of Leydig cells was appear as compared to control group of rats. [Figure $8 \mathrm{a}$ and $\mathrm{b}$ ], another section through the testes of formaldehyde treated group showed more histological changes in the testes including atrophy in the seminiferous tubules and highly vacuolation in the germinal epithelium with large space between the tubules [Figure 8c].

According to the previous studies, intra-peritoneal administration of FA at dose levels of $0.2,2$, and $20 \mathrm{mg} / \mathrm{kg}$ could cause degeneration and necrosis of spermatozoid in adulthood rats (Fishman et al., 2008). Our histological observations supported the effect of FA-exposed animals with increased percentage of immature, immotile, and dead sperms. Sperm quality and quantity are critical factors to the male fertility

(Handagama and Ariyaratne, 2001). A similar finding has been already reported by Karimov et al., 2003. Thus, it might be concluded that the chronic inhalation of FA can increase abnormal sperms. Therefore, early exposure to FA can result in drastic reduction in semen quality which in turn will lead to remarkable fertility problems.

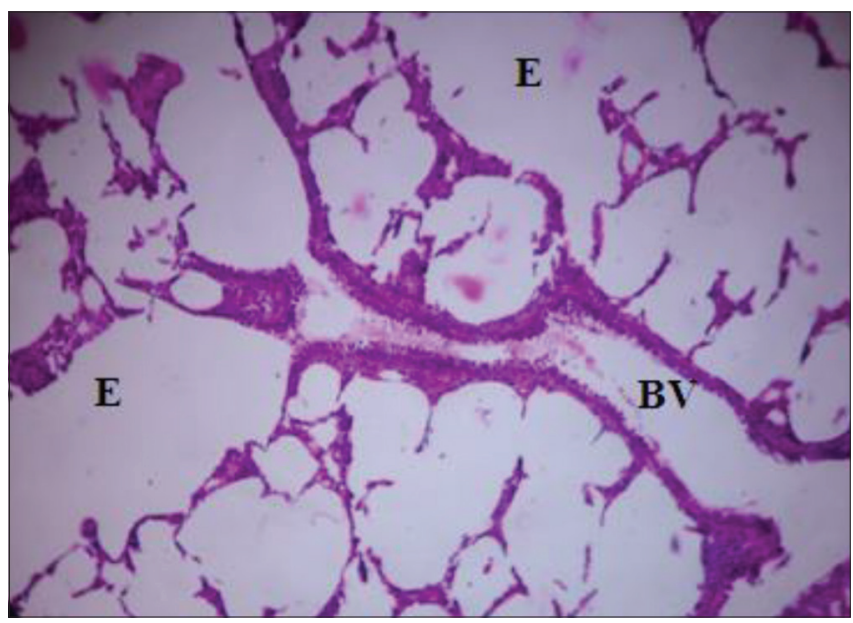

Figure 5: Section through the lung of xylene exposed group showing emphysema (E) and dilation in the blood vessel (BV) $100 x$

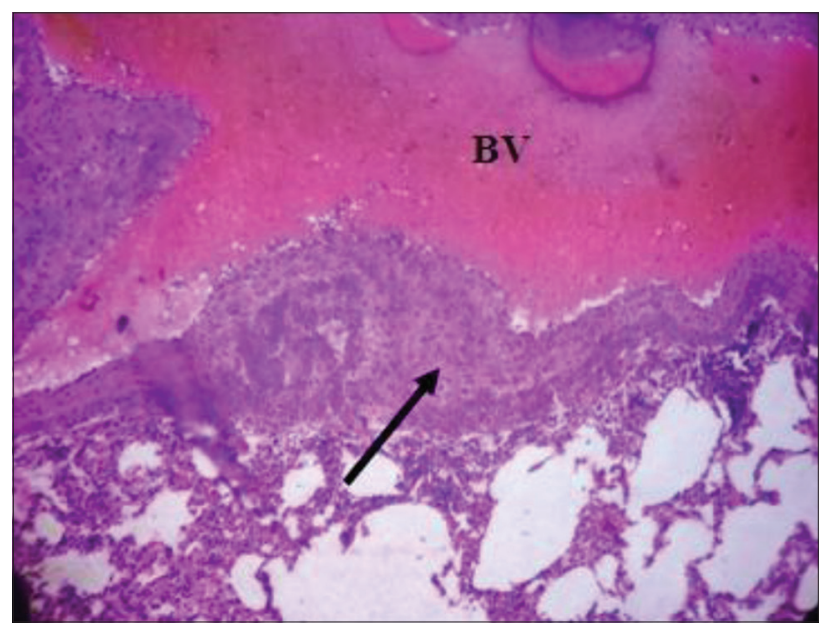

Figure 6: Section through the lung of xylene exposed group showing highly dilation of pulmonary blood vessele (BV) with hyperplastic smooth muscle of its wall (arrow) 100x

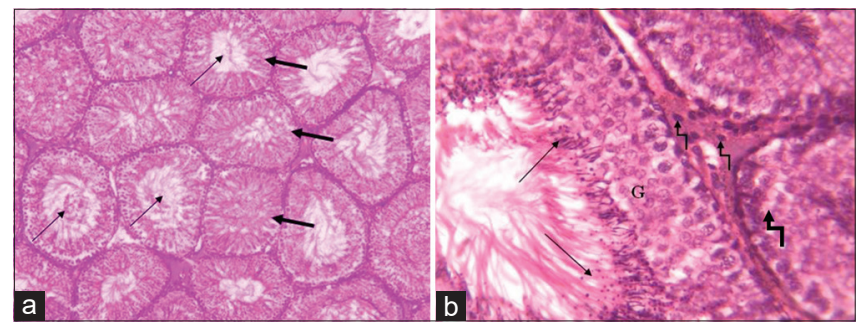

Figure 7: Section through the testis from control group showing normal appearance of the seminiferous tubules (thick arrow) with normal germinal epithelium (G), large number of sperms in the lumen of the seminiferous tubules (thin arrow) and normal number and appearance of Leydig cells (a) 100x, (b) $400 \times$ (H\&E)

Furthermore, xylene caused many histological alterations in the xylene treated group when compared with control group as in Figure $9 \mathrm{a}$ and $\mathrm{b}$ which include low number of sperms in the seminiferous tubules, large space between the tubules, decrease in the number of Leydig cells in the interstitial spaces between the seminiferous tubules, and 


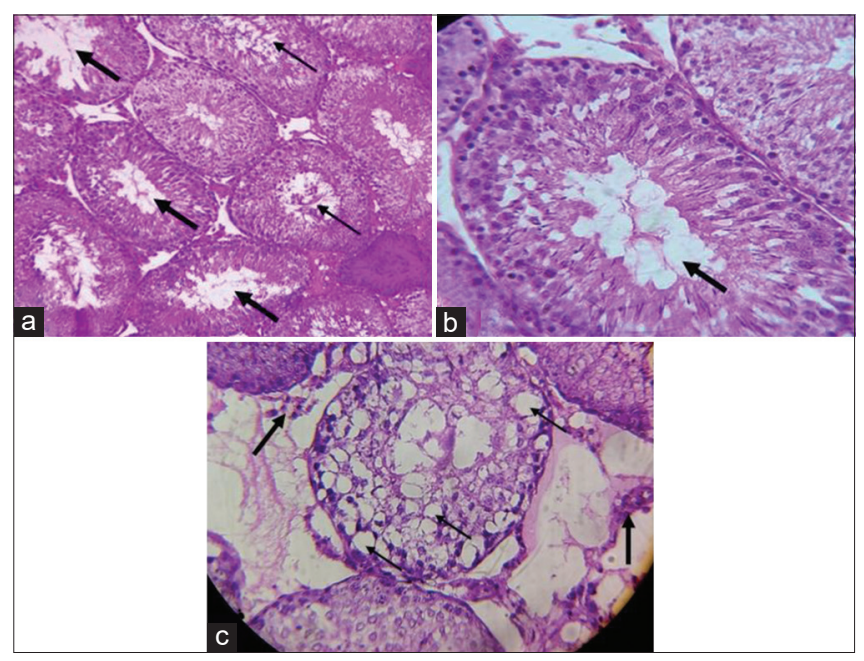

Figure 8: Section through the testis of formaldehyde treated group showing, (a) the lumen of the seminiferous tubules appear to be empty (thick arrow) or contain small number of sperms (thin arrow) 100x, H\&E. (b) Higher magnification of the same section showing the lumen of the seminiferous with few sperms (thick arrow) 400x, H\&E. (c) Another section from the same group showing highly vacuolation in the cytoplasm of the germ cell types (thin arrow) and large space between the tubules containing small number of Leydig cells in compare with control group (thick arrow) 400x, H\&E

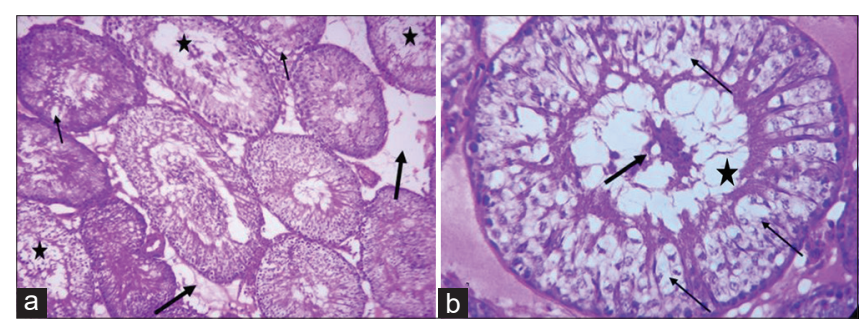

Figure 9: Section through the testis of xylene treated group showing, (a) seminiferous tubules some of them have degenerated germinal epithelium ( ), others with few vacuolation (thin arrow) and large space between the tubules with small numbers of Leydig cells (thick arrow) 100x, H\&E. (b) Higher magnification of the same section showing the lumen of the seminiferous containing different degenerated germ cells (thick arrow) and highly vacuolated germinale epithelial cells (thin arrow) 400x, H\&E

presence of vacuole in the germinal epithelium. OEHHA, 2012 founded that treated rats with intraperitoneal injection of xylene increased frequency of abnormal sperm, but only when the animals were housed at temperatures between 24 and $30^{\circ} \mathrm{C}$ (not at $20-24^{\circ} \mathrm{C}$ ).

Formalin and Xylene Effects on Sperm Abnormalities Different shapes of sperm abnormalities were seen in our study include Blunt hook sperm; coiled-tail sperm, and defective head sperm as in Table 1 and Figure 10.

Many changes have been reported in rabbit's testis after treatment with formaldehyde, in which the effects were severe in the form of decrease the sperm count, motility, and increase

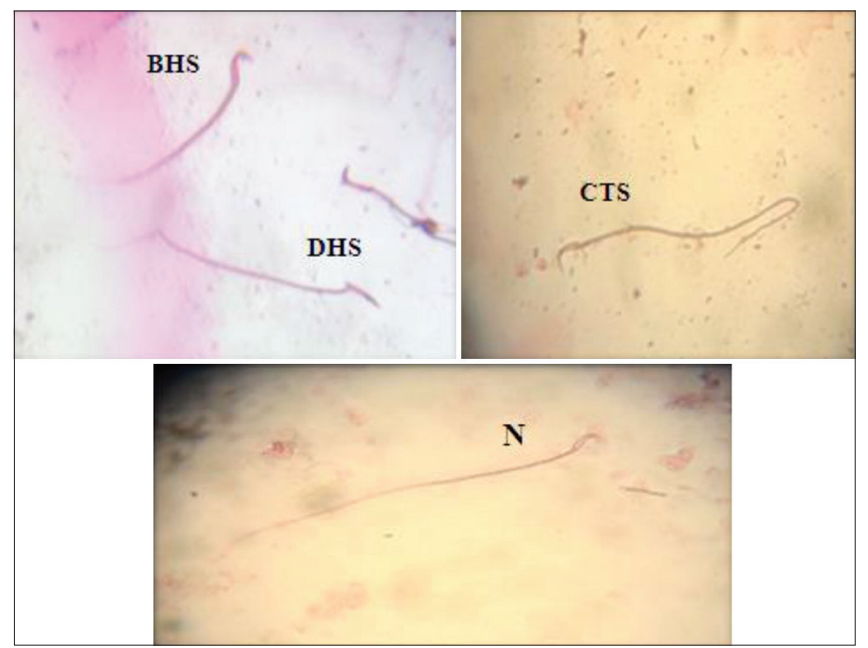

Figure 10: Effects of formaldehyde and xylene inhalation on sperm abnormalities; normal sperm (N); blunt hook sperm; coiled-tail sperm, and defective head sperm $40 x$

Table 1: Mean \pm S.E for the effect of inhalation of formaldehyde and xylene on sperm abnormalities in male rats

\begin{tabular}{lccc}
\hline \multirow{2}{*}{ Treatments } & \multicolumn{3}{c}{ Sperm abnormalities } \\
\cline { 2 - 4 } & BHS & CTS & DHS \\
\hline Control & $1.04 \pm 0.129$ & $0.02 \pm 0.023$ & $0.02 \pm 0.020$ \\
Formaldehyde & $2.50 \pm 0.17$ & $0.26 \pm 0.025$ & $0.17 \pm 0.025$ \\
Xylene & $1.56 \pm 0.068$ & $0.10 \pm 0.001$ & $0.08 \pm 0.021$ \\
\hline BHS: Blunt hook sperm, CTS: Coiled-tail sperm, DHS: Defective head \\
sperm
\end{tabular}

in the abnormal forms (George et al., 1999). Also the study of Cassidy et al. (1983) demonstrate that male rats dosed once orally with a $4 \% \mathrm{w} / \mathrm{v}$ formaldehyde solution at 100 or $200 \mathrm{mg} / \mathrm{kg}$ bw displayed a significantly increased incidence of sperm abnormalities (elongated and tapering heads).

Studies has been shown that formaldehyde and xylene toxicity can increase the production of reactive oxygen species (ROS) in testicular tissue, these including singlet oxygen, hydrogen peroxide, superoxide anions, and hydroxyl radicals which are important mediators of cellular injury and play an important role in oxidative damage (OEHHA, 2012; Gules and Eren, 2010; Rasyidah et al., 2014). Oxidative stress is an important mechanism of testicular damage. Excessive ROS increases apoptosis of germ cells, inhibits the activity of spermatozoa and causes infertility (Aitken et al., 2013; Aprioku, 2013). Furthermore, oxidative stress adversely affects cellular functions in various ways and has been linked to the development of testicular dysfunction and some other diseases (Odeigah, 1997).

The study of George et al., 2017, demonstrated that formaldehyde causes different histological changes in the liver, kidney, and testis of treated rabbits with decrease in the number of mature sperms compared to the control animals. 


\section{CONCLUSION}

The data of our study showed that inhalation the vapor of formaldehyde and xylene for one month (5 days a week) has degenerative effects on lungs and testes of the experimental rats as well as affecting on the spermatocytes and increased the frequency of sperm abnormalities; because of these substances are widely be used in laboratory works specially and other home used substances so good protected ways must be used to avoid these degenerative results.

\section{REFERENCES}

Aitken, R. J. and M. A. Baker. 2013. Causes and consequences of apoptosis in spermatozoa; contributions to infertility and impacts on development. Int. J. Dev. Biol. 57: 265-272.

AL-Saraj, A. and A. AL-Hubaity. 2003. Histological and histopathological changes of lung of rats during different periods of formaldehyde exposure. Iraqi J. Vet. Sci. 17(2): 111-121.

Aprioku, J. S. 2013. Pharmacology of free radicals and the impact of reactive oxygen species on the testis. J. Reprod. Infertil. 14(4): 158-172.

Arslan, A., B. Samanci, B. S. Samanci, H. Özevren and E. Deveci. 2016. Effects of xylene on respiratory mucosa in rats. Int. J. Morphol. 34(3): 934-938.

ATSDR. 2007. Toxicological Profile for Xylene. Agency for Toxic Substances and Disease Registry. U S Department of Health and Human Services, Public Health Service, Atlanta, GA.

Bancroft, J. D. and M. Gamble. 2002. Theory and Practice of Histological Techniques. $5^{\text {th }}$ ed. Churchill Livingstone, London. p165-180.

Cassidy, S. L., K. M. Dix and T. Jenkins. 1983. Evaluation of atesticular sperm head counting technique using rats exposed todimethoxyethyl phthalate (DMEP), glycerol-monochlorohydrin $(\mathrm{GMCH})$, epichlorohydrin $(\mathrm{ECH})$, formaldehyde (FA), or methylmethanesulphonate (MMS). Arch. Toxicol. J. 53: 71-78.

Collins, J. J. and G. A. Lineker. 2004. A review and meta-analysis of formaldehyde eexposure and leukemia. Regul. Toxicol. Pharmacol. 40(2): 81-91.

EPA. 2003. Toxicological Review of Xylenes. Environmental Protection Agency, Washington, DC.

EPA. 2012. Inhalation Health Effect Reference Values for Xylene. Environmental Protection Agency, U.S. Environmental Protection Agency Research Triangle Park, NC.

Feinman, S. E. 1988. Exposure to formaldehyde. In: Formaldehyde Sensitivity and Toxicity. CRC Press, Boca Raton. p17-36.

Fishman, A. P., J. A. Elias and L. R. Kaiser. 2008. Fishmans Pulmonary Diseases and Disorders. $4^{\text {th }}$ ed. McGraw-Hill Professional. London.

Fujimaki, H., Y. Kurokawa, N. Kunugita, M. Kikuchi, F. Sato and K. Arashidani. 2004. Differential immunogenic and neurogenic inflammatory responses in an allergic mouse model exposed to low levels of formaldehyde. Toxicology. 197(1): 1-13.

George, S. M., H. A. Yassa, H. A. Hussein and A. M. El Refaiy. 2017. Protective effect of L-carnitine against formaldehyde-induced kidney, liver and testicular damage in rabbits, a histopathological study. Mansoura J. Forens. Med. Clin. Toxicol. 25(2): 13-24.

George, S. M., H. G. Yassa and A. H. Hussein. 1999. The protective effect of L-Carnitine against sub-chronic toxicity of formaldehyde on rabbit's testicular functions. Mansoura J. Forens. Med. Clin. Toxicol. 19(2): 27-42.

Gules, O. and U. Eren. 2010. The effect of xylene and formaldehyde inhalation on testicular tissue in rats. Asian Austral. J. Anim. Sci. 23(11): 1412-1420.

Handagama, C. and S. Ariyaratne. 2001. Differentiation of the adult Leydig cell population in the postnatal testis. Biol. Reprod. 65: 660-671.

Jayalakshmi, K., H. Ravikumar, J. Naidu and R. Raghavendra. 2011. A silent killer in the laboratory-formaldehyde: Review of effects and management. Int. J. Oral Maxillofac. Pathol. 2(2): 13-19.

Karanowska, L. 1976. Chromosomal mutation. In: Sahai, R., editor. Advances in Cytogenetic and their Application in Livestock Improvement and Production. Vol. 35. N.D.R.I. Karnal, India. p166.

Karimov, K., S. H. N. Dadazhanov and M. S. Gildieva. 2003. Rat reproductive cells as biological indicators of the effect of enverionmental factors. Morfologiia. 123(1): 69-71.

Mohamed, A. M. T., M. El-Ashtokhy, H. M. Ahmed and O. Y. Ibrahim. 2012. Anatomical and histological effects of formaldehyde inhalation on the lung of albino Rat. Am. J. Sci. 8(9): 395-404.

Odeigah, P. G. C. 1997. Sperm head abnormalities and dominant lethal effects of formaldehyde in albino rats. Mutat. Res. J. 389: 141-148.

OEHHA. 2012. The Office of Environmental Health Hazard Assessment's. Evidence on the Developmental and Reproductive Toxicity of Xylene. California Office of Environmental Health Hazard Assessment, California.

OSHA. 1995. Occupational Exposure to Formaldehyde. U S Department of Labor Program Highlights, Occupational Safety and Health Administration, Washington, DC.

Ozen, O.A., N. Akpolat, A. Songur, I. Kus, I. Zararsiz, V. H. Ozcakmak and M. Sarsilmaz. 2005. Effect of formaldehyde inhalation on Hsp70 in seminiferous tubules of rat testes: an immunohistochemical study. Toxicol. Ind. Health J. 21(9): 249-254.

Pinkerton, L. E., M. J. Hein and L. T. Stayner. 2004. Mortality among a cohort of garment workers exposed to formaldehyde: An update. Occup. Environ. Med. 61: 193-200.

Rasyidah, T. I., S. Suhana, H. Nur-Hidayah, M. A. Kaswandi and R. M. Noah. 2014. Evaluation of antioxidant activity of Zingiber officinale (Ginger) on formalin induced testicular toxicity in rats. J. Med. Bioeng. 3(3): 149-153.

Razi, M., H. Malekinejad, R. Sayrafi, M. R. Hosseinchi, S. Feyzi, S. M. Moshtagion and H. Janbaz. 2013. Adverse effects of long-time exposure to formaldehyde vapour on testicular tissue and sperm parameters in rats. Vet. Res. Forum J. 4(4): 213-219.

Samuel, O., E. Ogbonnia, O. Uchewa, Onwe, A. Benedict, A. Christiana and E. Abakaliki. 2018. Histological and histochemical changes in the lung induced by short and long term exposure to xylene. World J. Pharm. Res. 7(15): 10-20.

Shrivastava, A. and Y. Saxena. 2013. Effect of formalin vapours on pulmonary functions of medical students in anatomy dissection hall over a period of one year. Indian J. Physiol. Pharmacol. 57(3): 255-260.

Turkoglu, A. O., M. Sarsılmaz, N. Colakoglu, I. Zararsız, T. Kuloglu, H. Pekmez and U. Tas. 2008. Formaldehyde induced damage in lungs and effects of caffeic acid phenethyl ester: A light microscopy study. Eur. J. Gen. Med. 5(3): 152-156.

WHO. 1999. International Program on Chemical Safety, Environmental Health Criteria. World Health Organization, Geneva.

WHO. 2006. IARC Monographs on the Evaluation of Carcinogenic Risks to Humans. World Health Organization, Geneva. 